\title{
A Preliminary Study on Green Building 3D Modelling Energy- saving Design Combined with Traditional Ecological Concepts
}

\author{
Runqi Qin ${ }^{* 1}$, Xinjian $\mathrm{Li}^{1}$ \\ ${ }^{1}$ School of Architecture, Southeast University, Nanjing, Jiangsu Province, China
}

\begin{abstract}
By combining the green ecological wisdom on traditional Chinese residential buildings, this paper summarized the ideas that can be used for references and applications in modern green energy-saving design. In addition, in view of the inherent shortcomings of traditional residential buildings, this paper proposed a green energy-saving design method for traditional residential buildings based on 3D modelling technology, which is complementary to the traditional ecological construction concept. Based on the establishment of a 3D building information model of traditional residential buildings, the optimal solution for the energy-saving design of green buildings is found through energy-saving adjustments to the building space structure and building spacing parameters.
\end{abstract}

\section{Introduction}

With the rapid development of China's economy, buildings are facing major energy supply challenges, and the concept of sustainable development continues to deepen. Green ecological buildings have become an important part of sustainable development.

Many efforts have been made to achieve the goal of reducing energy consumption. Among them, green roofs have been widely used since ancient times in both hot and cold climates [1]. Castleton et al. [2] extensively reviewed the existing literature to assess the potential building energy benefits of green roofs, and they reported that green roofs can significantly reduce the energy consumption from both winter heating and summer cooling in buildings with poor insulation. In contrast, other investigations [3] show that the feasibility of green roofs is very scarce when natural gas, electricity and water tariffs are considered in warm climates; and green roofs are very inconvenient when water costs are considered in cold climates. Furthermore, if the investment costs are considered, green roofs are not convenient energy refurbishments.

Although green building technology has made some progress, it still needs improvement [4]. Among buildings of different functional types, residential buildings can best reflect the close relationship between people and buildings. Traditional residential buildings also contain considerable green and energy-saving ecological wisdom, which is worthy of research and reference by contemporary designers.

Furthermore, with the development of computer technology, there is a new green energy saving methods. Recently, building information modelling (BIM) technology has been widely used as a digital design platform in green building design [5-8].

Traditional residential buildings with ultralow energy consumption need to combine local living habits and climatic conditions, learn from the inherent ecological ideas in traditional construction, and form targeted green and energy-saving designs. Moreover, since traditional houses use preindustrial construction technology and methods, there will be many shortcomings in the modern living environment that need to be improved. A previous study that analysed the occupants' responses to thermal discomfort in green and conventional buildings in New Zealand was reported that occupants in the green buildings had fewer environmental adjustments and more personal and psychological coping mechanisms than those in conventional buildings, which means that occupants in the green buildings had more access to building controls while the occupants in conventional buildings are not as dependent on the building design to moderate temperature and lighting [9].

Three-dimensional modelling technology can establish two-dimensional and three-dimensional information of a building at the same time and interface, can quickly and accurately obtain various parameters of the building and can adjust related parameters according to later needs with high accuracy and reliability as advantages.

Based on this concept, the author takes traditional houses in the area south of the Yangtze River as an example, analyses the spontaneously formed and perfected traditional construction wisdom in traditional houses, summarizes green ecological ideas that can be used for reference and discusses a green building energysaving design based on the 3D modelling technology method. 


\section{Green ecological ideas in traditional houses}

\subsection{Ecological wisdom in traditional residential buildings}

Since ancient times, China has had the traditional concept of "the unity of human and nature". This concept was used by ancient people in the construction of human settlements, forming a highly harmonious architectural form with nature.

At the macro level, when selecting sites for traditional residential buildings in China, people pay attention to local conditions, back mountains and face waters, coordinate natural factors such as the wind direction and solar radiation, and choose the best orientation of the local environment to ensure that the buildings get good sunlight and have comfortable indoor temperatures. In terms of spatial form, courtyards and patios are important spatial organization factors for traditional houses in southern China.

The climate in the area south of the Yangtze River is hot and humid, and a patio can be ventilated and dissipated, which can also help the layout of residential houses with narrow spacing and close lighting, as shown in Fig. 1. The "water in four directions converges into the courtyard" reflects the organization and drainage of the courtyard.

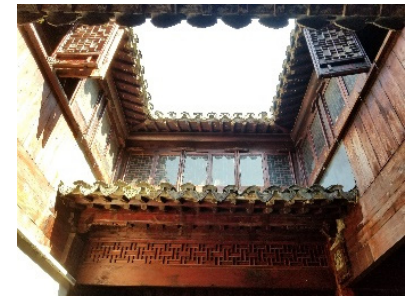

Fig1. Patio of traditional architecture in Nanxun

Traditional residential buildings also pay attention to "retaining wind and gathering gas". For example, a screen wall opposite a gate or inside a gate slows down the wind speed and avoids draughts [10].

In terms of building materials, we pay attention to local materials and have a strong sense of green ecology. For example, the area south of the Yangtze River is rich in water resources, so the commonly used building materials have low water absorption, strong moisture resistance and good durability. In the treatment of external walls, hollow wall masonry structures are commonly used as thermal insulation measures.

\subsection{Reference of traditional ecological thought to the design of green energy-saving buildings}

Under the guidance of traditional ecological wisdom, traditional Chinese houses have formed architectural forms that are compatible with local climatic conditions, geographical conditions, and humanistic conditions [11] and spontaneously formed a healthy balance between humans and nature. These traditional ecological wisdoms are also worthy of our reference and research today, and they have influenced and inspired the green ecological concept of modern buildings.
The first point is the layout between the buildings. The layouts of buildings in traditional settlements seem to be free and flexible, but in fact, they are reasonable. The layout of a building is generally related to the local wind direction, forming an air duct between the buildings [12]. This affects the natural ventilation inside and outside the building by removing heat, bringing in fresh air and increasing comfort in the hot summer [12].

The second point is the orientation of traditional houses. Buildings generally face south. That is, in accordance with the sunlight, more solar radiation can be obtained in winter. Combined with the locations and sizes of the windows, this can avoid western sunlight and receiving excessively high intensity and long sunlight during the hottest summer.

The third point is the layout of the space under eaves and patios. The space under the eaves of traditional houses in the area south of the Yangtze River is low. This forms a height difference with the high and deep patio, generates air pressure, and forms convection and good heat dissipation and ventilation effects[12].

The fourth point is the choice of building materials. Traditional residential buildings usually take local materials, account for the local climate and utilize material properties. Traditional houses in the area south of the Yangtze River mostly use brick and wood structures. Wood is relatively easy to obtain. Bricks are fired from clay. Bricks are usually used on the periphery to form an empty brick wall, which has a certain effect on heat preservation and heat storage.

\section{Shortcomings of traditional houses}

Traditional houses were spontaneously built people's ancestors, and they were constantly improved and transformed according to their living conditions. These houses were the result of simple design and planning. However, because there is no systematic coordination and planning, there are many shortcomings and defects in primitive traditional settlements and residential buildings.

First, the spacing of the buildings does not meet the relevant regulations. As time passes, the number of households gradually increases, and additional houses will appear. The traditional settlement streets that originally had a "land and material saving strategy [13]" became narrower and do not meet the requirements of fire protection regulations.

Second, the spatial structure is unreasonable. Through an investigation of the traditional residential settlements in the Nanjing area, it was found that the residents in the buildings have considerable debris piled up, there is no reasonable spatial division, and the evacuation channel is long and not clear. There is no proper placement of the kitchen, bathroom or bath space.

Although under the guidance of traditional wisdom the ecological awareness of residential buildings is worth learning, there are still shortcomings under modern norms and conditions. Researchers are required to combine traditional ecological thinking with modern technology, continuously improve energy-saving design methods, and create more standardized, liveable and energy-saving 
building forms.

\section{Energy-saving design of traditional residential green buildings based on 3D modelling technology}

The ecological wisdom of traditional residential buildings will inspire the green and energy-saving design of modern buildings, such as the layout and orientation of the buildings mentioned above, the choice of building materials, and the design of building shapes, including the ratio of eaves to patios and windows to walls. There is also the design of the building exterior wall structure.

Cho et al. [14] used the Energy Plus and IES software to conduct modelling and energy consumption simulations, respectively, and explored the best building orientation and window area. As shown in Table 1 and Table 2, the final results indicate that when the building model is facing the $0^{\circ}$ and $180^{\circ}$ directions, the total energy consumption including cooling and heating is the lowest. Therefore, the best building orientation is true south or true north. In addition, as the window area increases, energy consumption also increases.

Table 1. Energy Simulation Results Using Energy Plus. [14]

\begin{tabular}{|c|c|c|c|}
\hline \multicolumn{2}{|c|}{ Parameters } & Heating (GJ) & Cooling (GJ) \\
\hline \multirow{3}{*}{$\begin{array}{c}\text { Orientation } \\
\text { (window size }\end{array}$} & $0^{\circ}$ & $417,764.1$ & $275,803.1$ \\
\cline { 2 - 4 } 48 "x36") & $45^{\circ}$ & $417,765.1$ & $275,805.2$ \\
\cline { 2 - 4 } & $90^{\circ}$ & $417,765.8$ & $275,805.2$ \\
\cline { 2 - 4 } & $135^{\circ}$ & $417,766.1$ & $275,804.6$ \\
\cline { 2 - 4 } & $180^{\circ}$ & $417,765.2$ & $275,802.3$ \\
\hline \multirow{2}{*}{$\begin{array}{c}\text { Window } \\
(\text { Building } \\
\text { orientation } 0^{\circ} \text { ) }\end{array}$} & $24 \times 36$ & $417,755.5$ & $275,803.1$ \\
\cline { 2 - 4 } & $48 \times 36$ & $417,764.1$ & $275,803.1$ \\
\cline { 2 - 4 } & $72 \times 36$ & $417,772.9$ & $275,803.1$ \\
\hline
\end{tabular}

Table 2. Energy Simulation Results Using IES $<\mathrm{VE}>$. [14]

\begin{tabular}{|c|c|c|c|}
\hline \multicolumn{2}{|c|}{ Parameters } & Heating (GJ) & Cooling (GJ) \\
\hline \multirow{3}{*}{$\begin{array}{c}\text { Orientation } \\
\text { (window size }\end{array}$} & $0^{\circ}$ & 77.8 & 6.4 \\
\cline { 2 - 4 } 48 "x36") & $45^{\circ}$ & 78.0 & 6.5 \\
\cline { 2 - 4 } & $90^{\circ}$ & 78.3 & 6.5 \\
\cline { 2 - 4 } & $135^{\circ}$ & 78.3 & 6.5 \\
\cline { 2 - 4 } & $180^{\circ}$ & 77.9 & 6.3 \\
\hline \multirow{2}{*}{$\begin{array}{c}\text { Window } \\
\text { (Building } \\
\text { orientation } \\
0^{\circ} \text { ) }\end{array}$} & $24 " \mathrm{4} 36^{\prime \prime}$ & 77.8 & 5.9 \\
\cline { 2 - 4 } & 48 "x36" & 77.8 & 6.4 \\
\cline { 2 - 4 } & $72 " x 36 "$ & 77.9 & 6.9 \\
\hline
\end{tabular}

Combining the factors in traditional energy-saving technology with 3D modelling technology can effectively assist building energy-saving design.

First, we must establish a three-dimensional building information model corresponding to traditional houses. Second, based on the model, the space layout, building shape, material and structure of traditional residential buildings are designed; and the corresponding parameter values are adjusted and calculated to achieve the best energy-saving effect. The design steps are shown in Fig. 2.

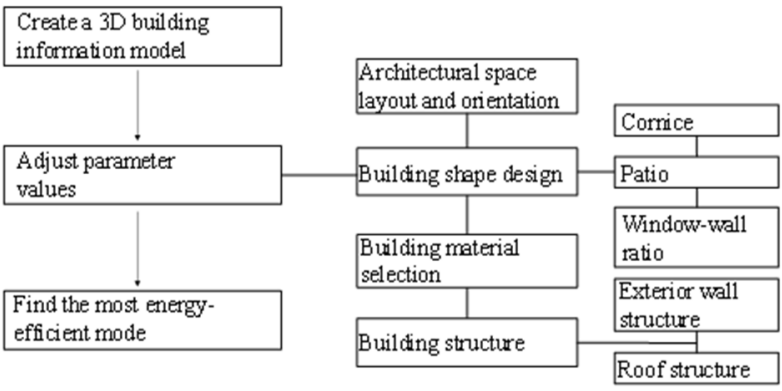

Fig2. Steps of building energy-saving design

\subsection{Establishment of $3 \mathrm{~d}$ building information model}

Taking the traditional residential buildings in Nanjing as an example, the Revit-Architecture software is used to build a three-dimensional building information model. In addition, the Ecotect software is used to analyze the environment in the area where a building is located; and on this basis, the parameters including building spacing, roof shape, building stories, window type, etc. are adjusted. Through the adjustment of the parameters, the best energy saving effect is achieved. Table 3 shows the green building energy-saving design parameters of some traditional residential buildings.

Table 3. Energy-saving design parameters of traditional residential green buildings in the Nanjing area.

\begin{tabular}{|c|c|c|}
\hline Item & Parameter name & Parameter value \\
\hline \multirow{4}{*}{$\begin{array}{l}\text { The outer } \\
\text { wall } \\
\text { structure of } \\
\text { Nanjing's } \\
\text { traditional } \\
\text { residential } \\
\text { buildings }\end{array}$} & $\begin{array}{l}\text { Cement mortar } \\
\text { protective layer }\end{array}$ & thickness $5.0 \mathrm{~mm}$ \\
\hline & $\begin{array}{l}\text { Autoclaved fly ash } \\
\text { brick }\end{array}$ & thickness $240.0 \mathrm{~mm}$ \\
\hline & Cement mortar & thickness $20.0 \mathrm{~mm}$ \\
\hline & Lime cement mortar & thickness $20.0 \mathrm{~mm}$ \\
\hline \multirow{4}{*}{$\begin{array}{l}\text { The roof } \\
\text { structure of } \\
\text { Nanjing's } \\
\text { traditional } \\
\text { residential } \\
\text { houses }\end{array}$} & Clay blue tile & thickness $20.0 \mathrm{~mm}$ \\
\hline & $\begin{array}{c}\text { Cement mortar (inner } \\
\text { layer) }\end{array}$ & thickness $40.0 \mathrm{~mm}$ \\
\hline & $\begin{array}{c}\text { Extruded polystyrene } \\
\text { board }\end{array}$ & thickness $50.0 \mathrm{~mm}$ \\
\hline & $\begin{array}{c}\text { Cement mortar (outer } \\
\text { layer) }\end{array}$ & thickness $20.0 \mathrm{~mm}$ \\
\hline \multirow{3}{*}{$\begin{array}{l}\text { The exterior } \\
\text { window } \\
\text { structure of } \\
\text { Nanjing } \\
\text { traditional } \\
\text { residence }\end{array}$} & $\begin{array}{c}\text { Ordinary glass (outer } \\
\text { layer) }\end{array}$ & thickness $6.0 \mathrm{~mm}$ \\
\hline & Air layer & thickness $12.0 \mathrm{~mm}$ \\
\hline & $\begin{array}{c}\text { Ordinary glass (inner } \\
\text { layer) }\end{array}$ & thickness $6.0 \mathrm{~mm}$ \\
\hline \multirow{2}{*}{$\begin{array}{c}\text { The } \\
\text { windows of } \\
\text { Nanjing's } \\
\text { traditional } \\
\text { houses face } \\
\text { love } \\
\text { condition }\end{array}$} & $\begin{array}{c}\text { South-facing window- } \\
\text { to-wall ratio }\end{array}$ & 0.4 \\
\hline & $\begin{array}{l}\text { North window-to-wall } \\
\text { ratio }\end{array}$ & 0.1 \\
\hline
\end{tabular}

As shown in Table 3, the 3D building information model of traditional residential buildings in Nanjing includes information on the exterior wall structure, roof structure, exterior window structure and window orientation. Combined with actual local conditions, through the continuous adjustment of these model 
parameters, the green and energy-saving design of traditional residential buildings can be realized.

\subsection{Spatial layout and body shape design among residential buildings}

In macro planning and design, the layout of a building should reasonably use solar radiation and wind direction to reduce energy consumption and create a comfortable environment.

Furthermore, the size of a building has an impact on energy savings. A building should choose a volume with a small figure coefficient, which will provide more heat in winter and less heat in summer [15].

Combining the local topography and landforms of traditional residential buildings, the building spacing is set to the best value. In addition to meeting the requirements of fire protection regulations, each building must receive sufficient sunlight to ensure that the winter temperature is not too low and save considerable air conditioning energy consumption.

The average environmental parameters of the Nanjing area in recent years were input into Ecotect software for environmental analysis. Then, according to the analysis results, the distance and angle between two adjacent traditional residential buildings were adjusted to achieve the best results.

\subsection{Energy-saving design of single residential buildings}

Traditional houses in the area south of the Yangtze River are generally 2-3 storey buildings, mainly brick-wood structures. Based on the abovementioned 3D modelling analysis, combined with the humid and rainy climate in the area south of the Yangtze River, which includes humid and hot summers, and cold winters, the following methods are briefly described:

First, the orientation of traditional houses determines how much solar radiation they receive. By adjusting the angle of the building, as mentioned above, the light intensity can also be increased by adjusting the window orientation angle to save costs. Double-layer hollow glass can be used to appropriately increase the window area of traditional houses. A bay window design can be adopted to select the best convex distance to achieve the best lighting efficiency.

Second, considering the thermal insulation requirements of residential buildings in the area south of the Yangtze River, the body shape coefficient of a building and the heat transfer coefficient of the outer envelope structure can be adjusted to achieve a benign balance, which can meet the thermal insulation demand.

Third, the design of overhanging eaves can be optimized. There are many overhanging eaves in the area south of the Yangtze River dwellings. Overhanging eaves affect indoor brightness and have the effect of allowing rain to roll off. Combined with the 3D model, the width of the eaves can be adjusted to ensure that a room is not affected by the wind and rain and the indoor brightness is appropriate.
In summary, a 3D building information model corresponding to traditional residential buildings is established, its own spatial structure and body shape are designed for energy savings, and the building spacing is adjusted to create an energy-saving and comfortable building form.

\section{Conclusion}

By analyzing the traditional ecological construction methods in the area south of the Yangtze River, summarizing traditional ecological thoughts worthy of reference and research, and addressing the shortcomings caused by the inconsistency of traditional methods with the modern environment, a traditional residential green building energy-saving design method based on 3D modelling technology is proposed. This method can systematically optimize the building environment, materials, building spacing, window-to-wall ratio and other related parameters so that modern technology and traditional ecological construction concepts complement each other.

\section{Acknowledgments}

The authors wish to acknowledge the financial support of the National Natural Science Foundation of China (NSFC, No. 51678129) and the Jiangsu Provincial Department of Culture and Tourism (No. 2019SK03).

\section{References}

1. R.M. Lazzarin, F. Castellotti, F. Busato, Energ Buildings. 37, 1260-1267 (2005).

2. H.F. Castleton, V. Stovin, S.B.M. Beck, J.B. Davison, Energ Buildings. 42, 1582-1591 (2010).

3. F. Ascione, N. Bianco, F. de Rossi, G. Turni, G.P. Vanoli, Appl Energ. 104, 845-859 (2013).

4. N. Zhang, X. Liu, Architecture Technology. 48, 158160 (2017).

5. H. Xia, K. Yi, Study on Collaborative Design of Green Building Based on BIM Technology. 2013, Springer Berlin Heidelberg: Berlin, Heidelberg. p. 921-928.

6. T. Wei, Y. Chen, J Amb Intel Hum Comp. 11, 3699$3706(2020)$.

7. K.S. Abhinaya, V.R.P. Kumar, L. Krishnaraj, International Journal of Renewable Energy Research. 7, 1675-1681 (2017).

8. Z. Yuan, J. Zhou, Y. Qiao, Y. Zhang, D. Liu, H. Zhu, Sustainability (Basel, Switzerland). 12, 7862 (2020).

9. N.S.M. Azizi, S. Wilkinson, E. Fassman, Energ Buildings. 104, 191-198 (2015).

10. J. Wang, The ecological concepts of Chinese traditional residential buildings in the application of energy-saving design of the green building, East China Jiaotong University, (2013).

11. M. Wang, Research on influencing factors of green 
building promotion, Capital University of Economics and Business, (2014).

12. L. Bao, Architect. 132, 5-12 (2008).

13. J. Xu, Z. Wu, Y. Liu, Z. Shu, W. Yang, Y. Wei, Industrial Construction, 49, 1-6 (2019).

14. C. Cho, D. Chen, S. Woo, Journal of KIBIM. 2, (2012).

15. T. Liu, China Forest Products Industry. 44, (2017). 